\author{
بررسى اثرات برداشت شن و ماسه بر ويزّى هاى ريختسنجى رسوبات بستر \\ (مطالعه موردى: رودخانه زارم رود، استان مازندران) \\ سيد حسين روشان'، قربان وهابزاده'، كريم سليمانى' و عبدالواحد خالدى درويشان'

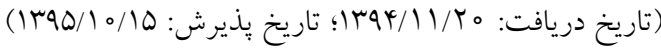

حكکله

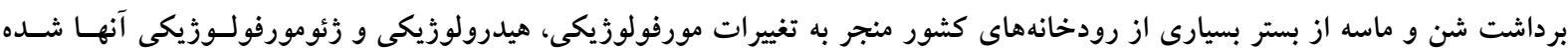

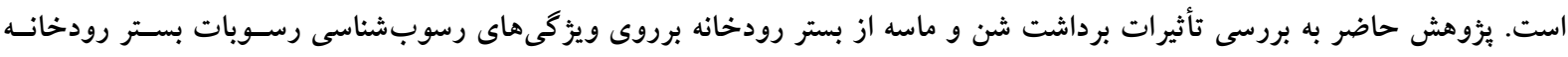

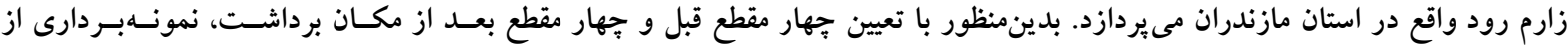

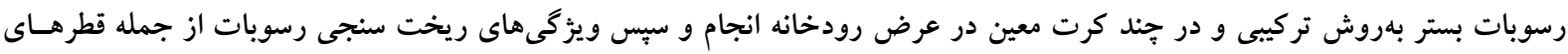

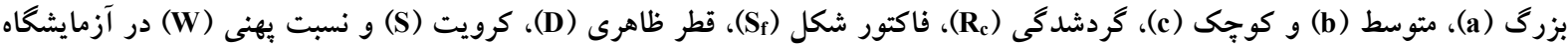

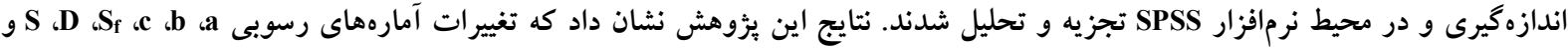

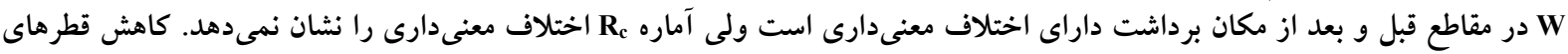

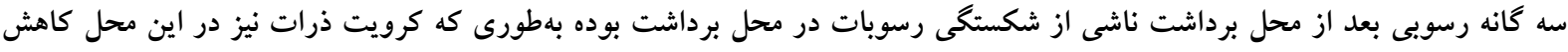

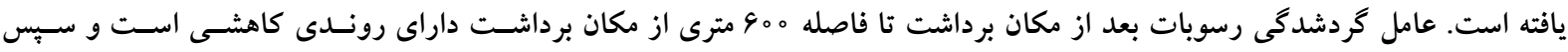
افزايش بيدا مى كند.

وازههاى كليدى: برداشت شن و ماسه، روش تركيبى، ريخت سنجى رسوبات، استان مازندران

\footnotetext{
ا.كروه علوم و مهندسى آبخيزدارى، دانشكده منابع طبيعى، دانشخاه علوم كشاورزى و منابع طبيعى سارى

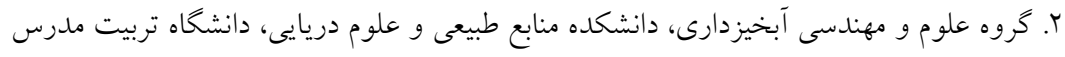

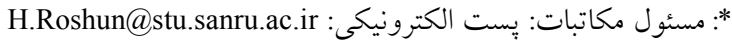


زيرساختها از جمله آبشستخى بايه يل هـا و در معسرض قـرار

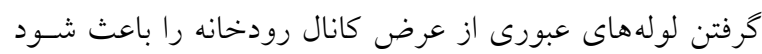

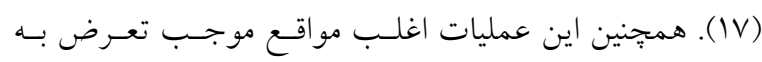
اراضى در مناطق با تراكم جمعيتى بالا شده كه مهمتسرين نتسيج

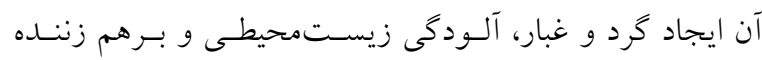

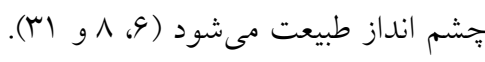

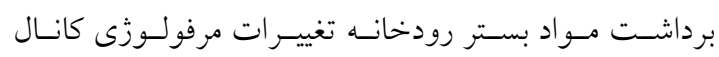

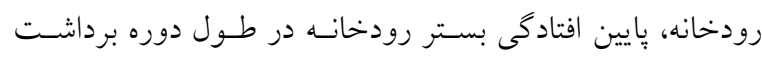

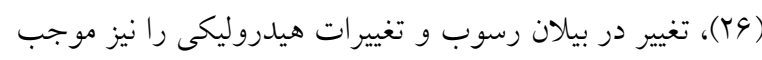

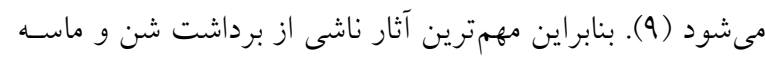

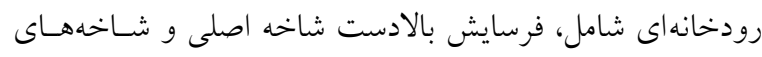

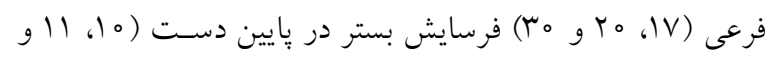

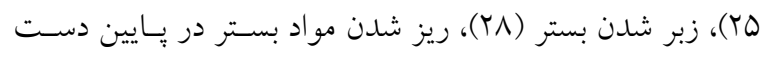

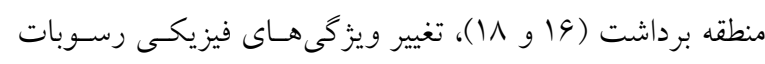

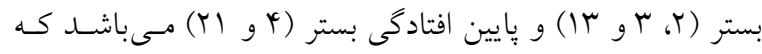

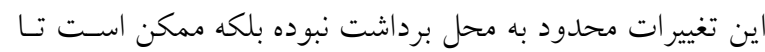

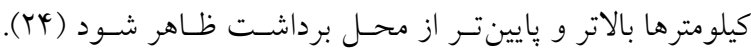

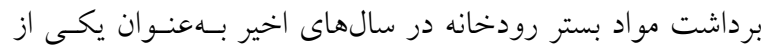

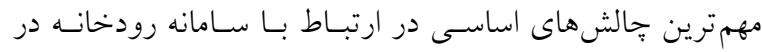

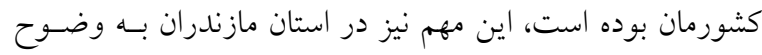
ديده مى شود. بهطورى كه بهدليل برداشت بىرويه شن و ماسه از

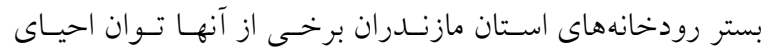

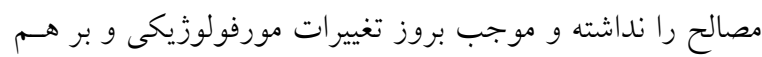

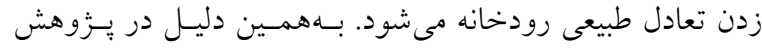

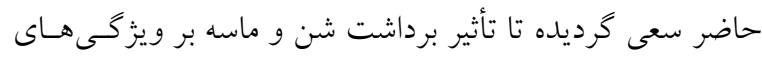

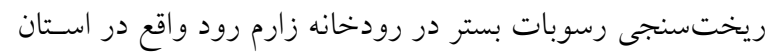
مازندران مورد مطالعه قرار كيرد.

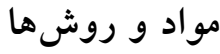

حوزه آبخيز رودخانه زارم رود در شمال ايران در بخش مركزى

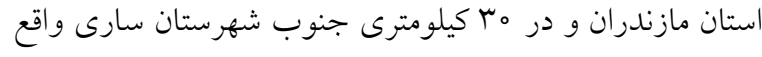
شده است. ايـن حسوزه از نظـر جغرافيـايى بـين طـول شـرقى

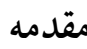

امروزه در سراسر جهان و از جمله در كشورمان، انسواع مصـالح

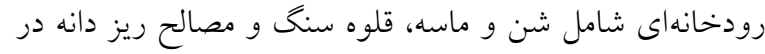

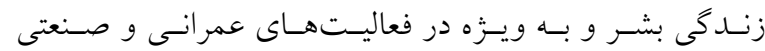

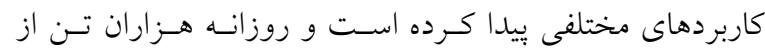

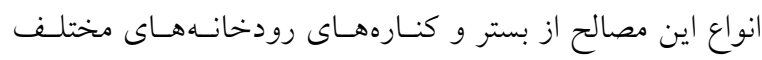

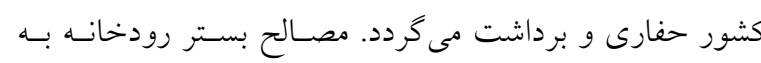

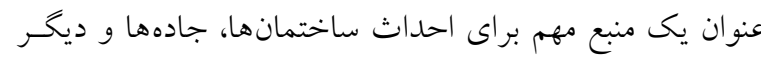

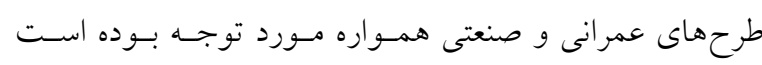

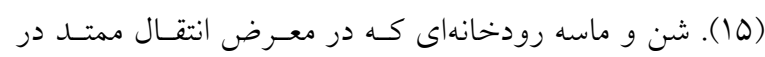

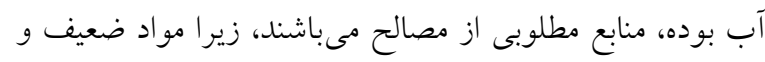

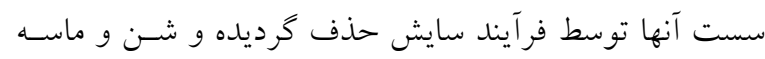

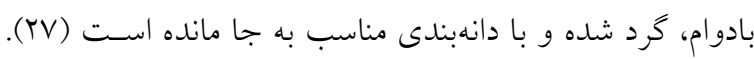

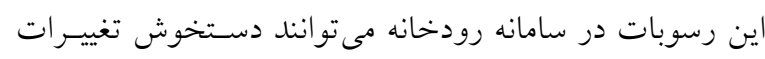

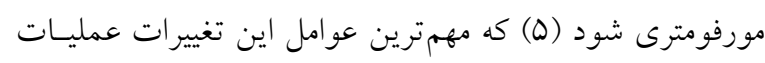

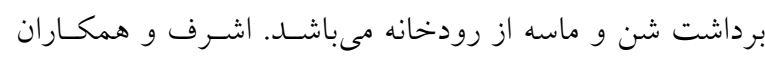

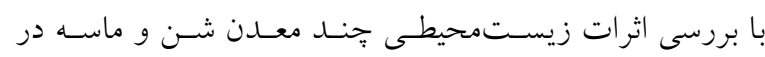

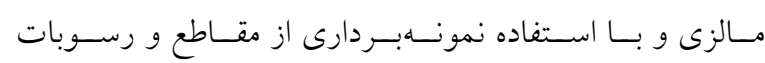

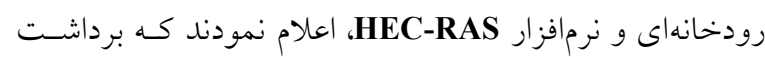

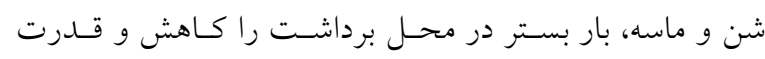

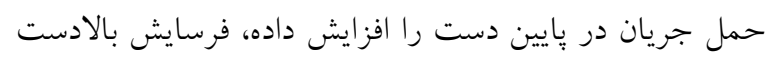

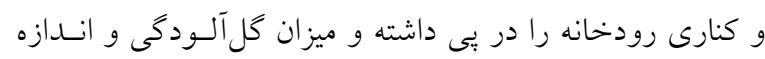

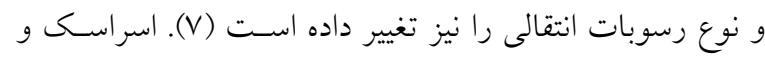

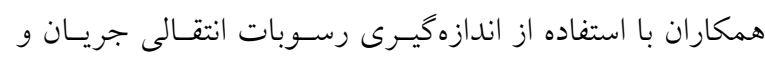

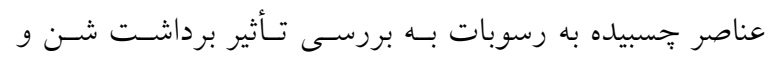

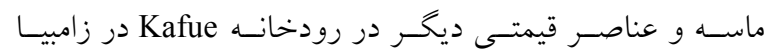

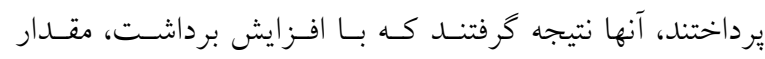

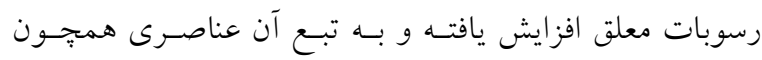

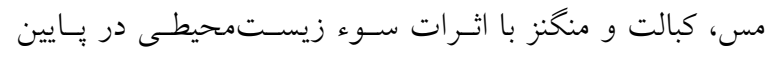

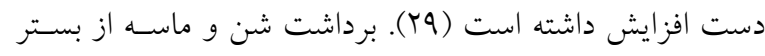

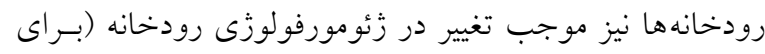

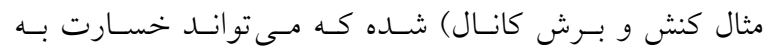




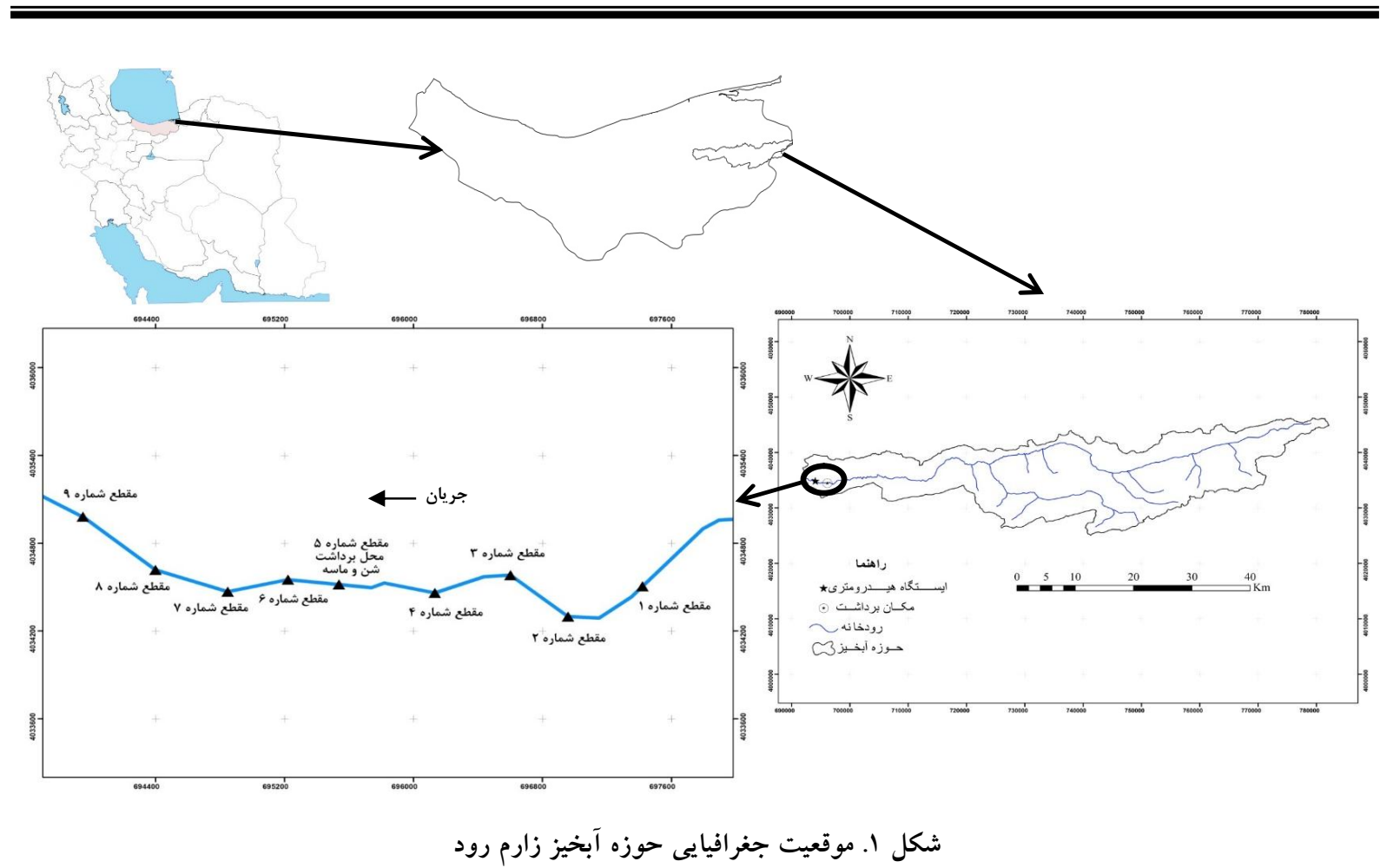

رود انجام مىشود. بلمنظور مشخص نمودن مكان برداشت شن

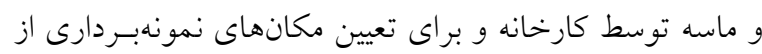

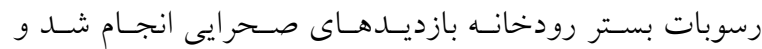

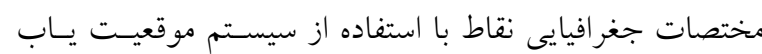
جهانى بهدست آمد. جهت بررسى اثرات برداشت در بازه مورد

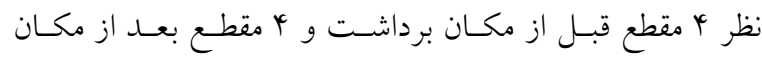

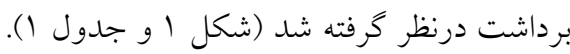

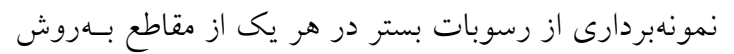

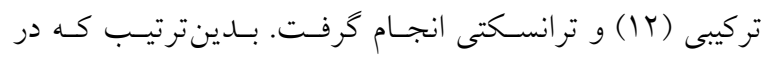

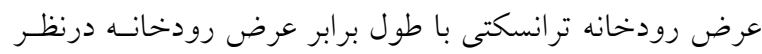

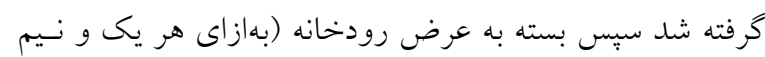

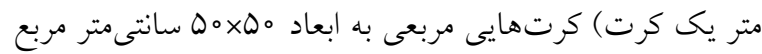

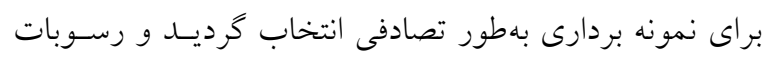

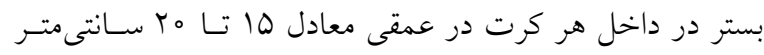

$$
\text { برداشت شدند (شكل Y). }
$$

سبس نمونههاى برداشت شده از كرتها در هر مقطع با هم

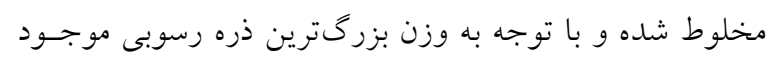

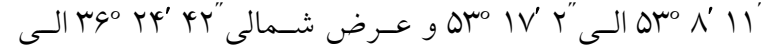

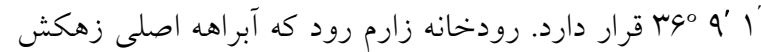

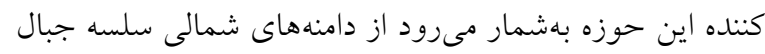

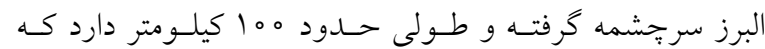

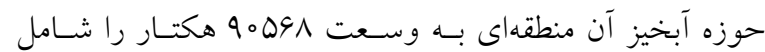
مى گردد (شكل (). محدوده مورد مطالعه براى بررسى اثرات اتهرئ

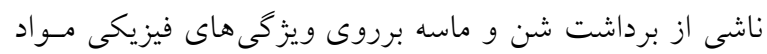

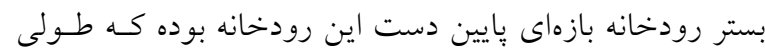

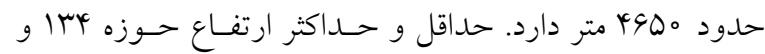

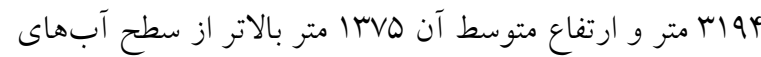

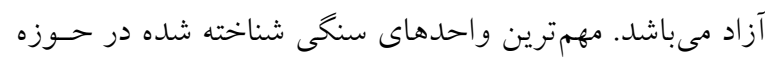

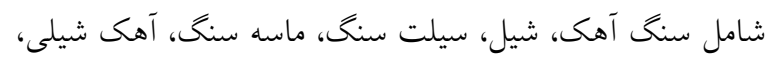
دولوميت، كنخلومر او رسوبات آبرفتى مىباشند.

\section{روش انجام تحقيق}

برداشت شن و ماسه در حال حاضر توسط يك كارخانسه فعـال

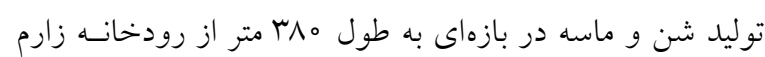




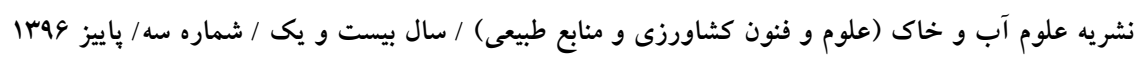

\begin{tabular}{|c|c|c|c|c|c|}
\hline \multirow{3}{*}{ شماره مقطع } & \multicolumn{4}{|c|}{ جدول ا. موقعيت جغر افيايى مقاطع برداشت نمونههاى مواد بستر رودخانه } & \multirow{3}{*}{ موقعيت مقاطع } \\
\hline & \multicolumn{2}{|c|}{ موقعيت جغرافيايى } & \multirow{2}{*}{ ارتفاع از سطح دريا } & \multirow{2}{*}{ فاصله بين مقاطع } & \\
\hline & طول شرقى & عرض شمالى & & & \\
\hline 1 & $\Delta \mu^{\circ} \mid r^{\prime} 10^{\prime \prime}$ & $r Q^{\circ} r D^{\prime} \Delta Y^{\prime \prime}$ & $19 V$ & $\circ$ & \multirow{4}{*}{ مقاطع بعد از مكان برداشت } \\
\hline r & oro $11^{\prime} \mathrm{Yq}^{\prime \prime}$ & 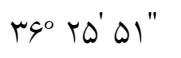 & 191 & $\Delta \wedge \circ$ & \\
\hline r & 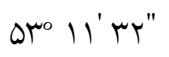 & 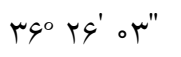 & Y०o & $\varphi \wedge 。$ & \\
\hline c & oro $1 l^{\prime} \mid Y^{\prime \prime}$ & rq $\varphi^{\circ} \varphi^{\prime} \circ l^{\prime \prime}$ & rol & $\Delta \wedge \circ$ & \\
\hline$\Delta$ & $\Delta H^{\circ} \rho^{\prime}{ }^{\prime} \Delta Y^{\prime \prime}$ & 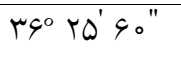 & $r \circ r$ & roo & محل برداشت شن و ماسه \\
\hline 4 & $\Delta \mu^{\circ} 10^{\prime} k Y^{\prime \prime}$ & $r \varphi^{\circ} Y Q^{\prime} \Delta Q^{\prime \prime}$ & Y०Y & щ人。 & \multirow{4}{*}{ مقاطع قبل از مكان برداشت } \\
\hline V & 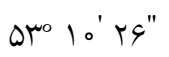 & rG r & $r \circ D$ & $\Delta \wedge \circ$ & \\
\hline$\wedge$ & Q & rG $\varphi^{\circ} \varepsilon^{\prime} \circ \Lambda^{\prime \prime}$ & $r \circ \varphi$ & $\Delta \wedge \circ$ & \\
\hline 9 & $\Delta \mu^{\circ} \circ q^{\prime} \nvdash \Lambda^{\prime \prime}$ & rG $\varphi^{\circ} \varphi^{\prime} I V "$ & $r \circ V$ & $\Delta \wedge \circ$ & \\
\hline
\end{tabular}

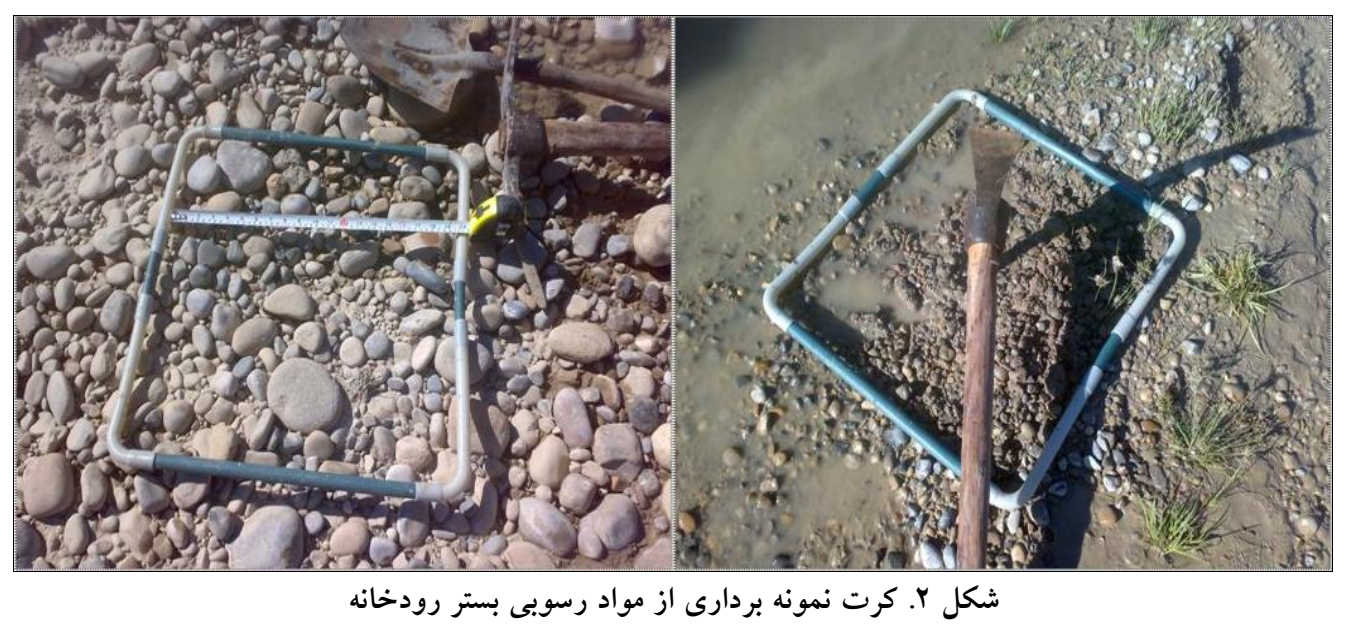

مخلوط شدند (19 و Y Y). سيس نمونها در درون ظـرفهـاى

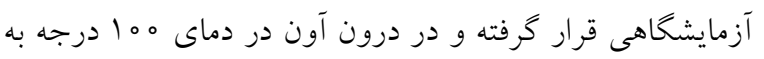

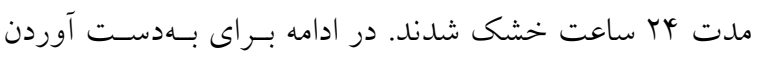
قطر بزرگ، قطر متوسط و قطر كوجــ ذرات رسـوبى ابتـدا از رسوبات هر مقطع به طور تصادفى ه ا نمونسه رسـوب درشـت (ابعاد ذرات بهصورت دامنه

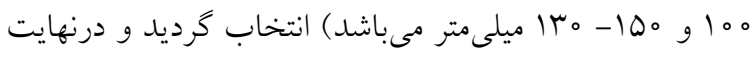
بـا اسـتفاده از كــوليس، خــط كـش ميلـىمتـرى و كر اولـومتر

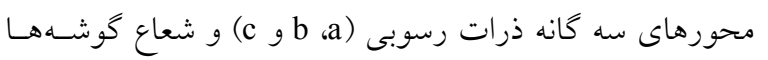

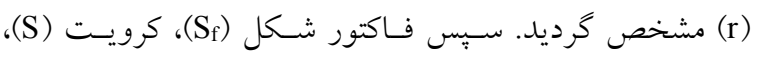

در داخل نمونهها، وزن نمونه برداشتى مشخص شد، بـهــورى

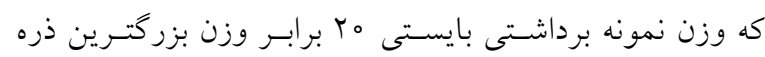

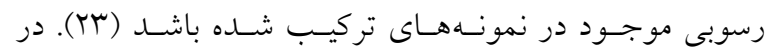
مجموع تعداد ها كرت نمونه رسوب از كليه مقـاطع برداشـت

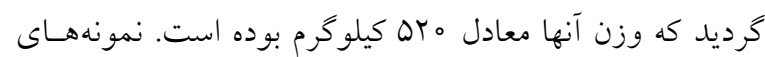

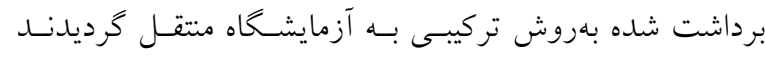
بهعبارت ديخر تمامى نمونههاى برداشت شده از يك مقطع (سه به بـ تا ينج نمونه بسته به عرض و شرايط مقطع رودخانه) مجدداً بـا يكديخر تركيب شده و بهعنوان يك نمونه از مقطـع مـورد نظـر

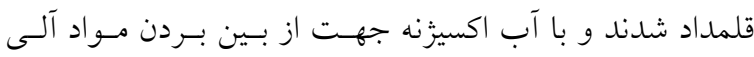


بررسى اثرات برداشت شن و ماسه بر ويزگى هاى ريختسنجى رسوبات بستر ...

جدول r. روابط مورد استفاده براى بهدست آوردن خصوصيات ريختسنجى رسوبات

\begin{tabular}{|c|c|c|c|c|c|}
\hline 0 & $\varphi$ & $r$ & r & 1 & رديف \\
\hline $\mathrm{N}_{\mathrm{d}}=\frac{\mathrm{b}}{\mathrm{k}}$ & $\mathrm{W}=\frac{\mathrm{a}+\mathrm{b}}{\mathrm{rc}}$ & $\mathrm{R}_{\mathrm{c}}=\frac{\mathrm{r}^{r}}{\text { a.b.c }}$ & $\mathrm{S}=\frac{\mathrm{N}_{\mathrm{d}}}{\mathrm{a}}$ & $\mathrm{S}_{\mathrm{f}}=\frac{\mathrm{c}}{\sqrt{\mathrm{ab}}}$ & رابطه \\
\hline
\end{tabular}

كاهش يافته است كه برداشت شـن و ماسـه از بسـتر رودخانسه (مقاطع ه) شدت اين روند را بيشتر كرده، بهطورى كه مىتـوان نتيجه كرفت كه فعاليـت هـاى برداشـت شـن و ماسـه موجـبـ تفكيك رسوبات در قطرهـاى مختلـف شـده و موجـبـ تغييـر نسبت آنها مىشود. بنابراين برداشت شن و ماسه موجب تغييـر در اندازه متوسط ذرات رسوبى در مقـاطع يـايين دسـت مكـان برداشت شده كه با نتايج (آ، 19 و 11) مطابقت دارد. تغييـرات آماره رسوبى كرويت در مقاطع قبل از مكان برداشت تـا محـل برداشت داراى روندى افزايشى بوده كه در محل برداشـت كـهـ حفرهها و جالههايى توسط ماشين آلات ايجاد مىشود با كاهش محسوسى روبهرو شده كه ناشى از شكسـتحى و ريزتـر شـدن ذرات رسوبى در اين محل مىباشد (جدول \&). از طرفى تركيب رسوبات لايههاى زيرين و سطحى بستر رودخانه در اثر حفر و

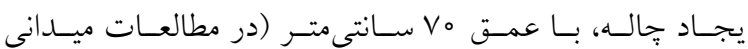
اندازه گيرى شد) موجب مخلوط شدن مواد رسـوبى قـديمى و

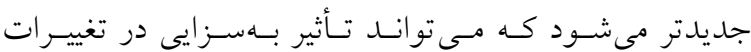
ويثزى هاى ريخت سنجى رسوبات در مكـان برداشـت داشـته باشد. مقدار كردشدگى رسوبات رودخانهاى نيز در بـازه مـورد مطالعه نيز از بالا دست بـهسمت قِـايين دسـت داراى رونـدى افزايشى مىباشد. نسبت بهنى در مقاطع بعد از مكـان برداشـت افت داشته و ميزان آن در مقايسه با مقاطع قبل از مكان برداشت كمتر شده است. مهمترين عامل آن كاهش مقدار قطر بـزرگ و متوسط رسوبى بوده كه ناشى از فعاليتهاى برداشت در مقطع ه مىباشد (جدول \&). با توجه به رابطه نسبت بهنسى كـه داراى مبناى مشابه ضريب شكل بوده و بر اساس اقطار سه كانه ذرات رسوبى تعبين مى شود. نسبت بهنى از يك بيش تر بوده و مقـدار

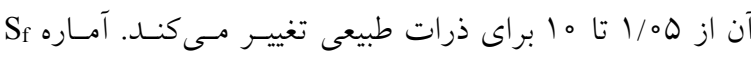
داراى روند كاهشى بين مقاطع بعد از محل برداشت نسـبت بـهـ

\begin{tabular}{|c|c|c|c|c|}
\hline $0 / 9$ & $\circ / V$ & $\circ / 0$ & $\circ / \mu$ & $\mathrm{S}_{\mathrm{f}}$ \\
\hline 1 & $1 / 00$ & $1 / 1 \pi$ & $1 / T V$ & $\mathrm{~K}$ \\
\hline
\end{tabular}

كردشدگى (Rc)، نسبت يهنى (W) و قطر ظـاهرى ذره رسـوبى

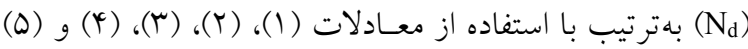
محاسبه شد (جدول r ) (1) (1) ثابت ماركويك (K) نيز براى تعيين قطر ظاهرى ذره رسوبى از جدول (r) بهدست آمد. بهمنظور بررسى اختلاف معنىدارى آمارههاى رسوبى اندازه

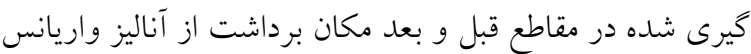

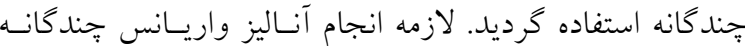
اطمينان از نرمال بودن و همخنى دادههـا مسىباشـــ كـه در ايـن

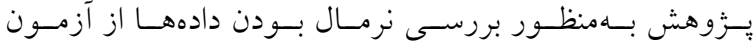
كلمو گروف- اسميرنوف و جهت تست همخنى از آزمون ليـون در محيط نرمافزار SPSS22 استفاده گرديد. آماره رسوبى R در مر مر سطح 90 درصد نرمال نبوده ولـى بقيسه آمـارههـا در سـطح 90 درصد نرمال بودند. بنابراين براى بررسى اختلاف معنىدار بودن

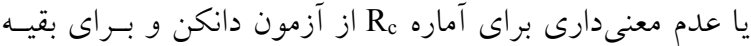
آمارهها از آزمون توكى استفاده كرديد.

\section{نتايج و بحث}

ويزگى هاى فيزيكى رسوبات از جمله محورهاى سه گانه ذرات رسوبى، گردشدگى، ضـريب شـكل، قطـر ظـاهرى، كرويست و نسبت يهنى براى تمامى مقاطع به دست آمد درنهايت آمارههاى توصيفى ويزگ گى هاى فيزيكى رسوبات بـا اسـتفاده از نــرمافـزار SPSS22 استخراج گرديدند (جدول عأو ه). بهطور كلى، توزيع اندازه مواد بستر در جهت بـايين دسـت 
نشريه علوم آب و خاك (علوم و فنون كشاورزى و منابع طبيعى) / سال بيست و يك / شماره سه/ إييز وها1

\begin{tabular}{|c|c|c|c|c|c|c|c|c|c|}
\hline \multicolumn{9}{|c|}{ مقطع برداشتى نمونه } & \multirow{2}{*}{ آماره رسوبى } \\
\hline 9 & $\wedge$ & v & 9 & 0 & r & r & r & 1 & \\
\hline$Y T / D$ & $\hat{k y / 9}$ & $49 / 1$ & $49 / 9$ & $90 / V$ & $V 9 / 1$ & $19 / 9$ & $99 / V^{\circ}$ & 101 & قطر بزرى (a) (mm) \\
\hline 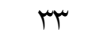 & 荭 & re/o & $r \Delta / r$ & $r q / 9$ & $\Delta F / \mu$ & $9 \pi / V$ & GY/AF & $90 / \circ$ & قطر متوسط (bm) (m) \\
\hline$|1 / 9|$ & $\mid N / \uparrow \Lambda$ & $r \circ / 90$ & $M T / 09$ & TY/TA & $r q / \Lambda$ & $r T / 9$ & rV/AT & $r r / l$ & قطر كوجى (cm) (mm) \\
\hline $0 / 019$ & $\circ / 0 \circ \mathrm{VI}$ & $\circ / 0 \circ 00$ & $\circ \% \circ V T$ & $0 / 011$ & $\circ / 0 \circ \wedge t$ & $0 / 0091$ & $\circ / 0001$ &.$\% \circ 40$ & كردشدگى (Rc) \\
\hline$\circ / \Delta V T$ & O/GYA & $\circ / 0 r_{0}$ & 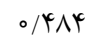 & $\circ / 0 V Q$ & $0 / 499$ & $\circ / 4 \mu_{0}$ & $\circ / 4 \vee \circ$ & OAYV & ضريب شكل (Sf) \\
\hline$r q / . q 4$ & $r \circ / 0 \circ \Lambda$ & r०/rद. & $r \wedge / q \circ \wedge$ & Tr/VTG & $Y Q / \mu Y V$ & $\Delta T / V V 。$ & $\Delta G / Y Y M$ & DQ/VTr & قطر ظاهرى (Dm) (m) \\
\hline.$/ 9 \mathrm{VQ}$ &.$/ 9 \wedge 0$ & $0 / 944$ & O/GYA &.$/ 091$ & $0 / 904^{4}$ & $\circ / \Delta \wedge \vee$ &.$/ 090$ & $\circ / \Delta \Delta \Delta$ & كرويت (s) \\
\hline $1 / 190$ & $r / M T$ & $T / \circ T_{\Lambda}$ & $1 / 194$ & $r / T 90$ & $r / r \wedge 。$ & T/TYV & $r / T ו 1$ & $r / 919$ & نسبت يهنى (w) \\
\hline
\end{tabular}

\begin{tabular}{|c|c|c|c|c|c|c|c|c|c|}
\hline \multicolumn{9}{|c|}{ مقطع برداشتى نمونه } & \multirow{2}{*}{ آماره رسوبى } \\
\hline 9 & $\wedge$ & V & 9 & 0 & $r$ & r & r & 1 & \\
\hline$\mu \mu / 。$ & $F r / 0$ & $\mu y / 0$ & $\uparrow V / \circ$ & $\Delta V / \circ$ & $V \Psi / D$ & $90 / 0$ & $111 / 0$ & 119 & قطر بزرى (a) (mm) \\
\hline me & rI/D & re/o & $r q / \circ$ & $\varphi_{0} / \circ$ & $\Delta \psi / r$ & $94 \%$ & $99 / 0$ & $V / \Delta$ & قطر متوسط (bm) (mm) \\
\hline $\mathrm{IV} / 0$ & $11 / 0$ & $19 / 1$ & $T Y / 0$ & $Y Y / 0$ & TN/Q & $M y / 0$ & rN/D & $\mathrm{rV} / \mathrm{d}$ & قطر كوجى (c) (mm) \\
\hline$\circ / \circ V Q$ & ०/O०Y० & \%OYQ & OOOFT & ०/O०I & .10090 & OOOFY & OOOKY &.$/ 001 \mathrm{~V}$ & كردشدكى (Rc) \\
\hline o/DFF & $0 / 911$ & o/Drq & $\circ / 4 v$ & ०/QY० & O/FYT & $0 /$ pry & - MAN & $0 / 490$ & ضريب شكل (Sf) \\
\hline TV/rTr & rV/NTr & ro/D9r & TH/OH & TI/MY & (FT/NA & $\Delta r / 0 G 4$ & $91 / 411$ & GM/YHA & قطر ظاهرى (Dm) (m) \\
\hline $0 / 94 \mathrm{kT}$ & $0 / 94 \wedge$ & $0 / 9 V T$ & $0 / 9 Y \Lambda$ & ०/OHA &.$/ 094$ &.$/ 0 \wedge \mu$ & $\circ / Q Y Q$ &.$/ 090$ & كرويت (s) \\
\hline INT。 & $1 / 910$ & $1 / 94 V$ & 1/V9。 & r/TYq & $r / r q r$ & T/YYYO & T/MG & $r / \wedge 9 \circ$ & يهن شدكى (w) \\
\hline
\end{tabular}

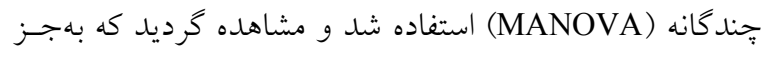

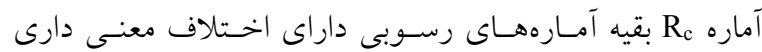

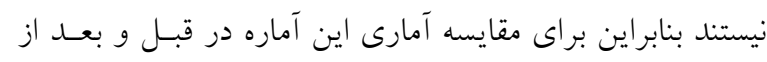

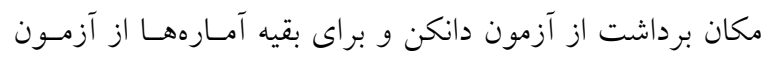

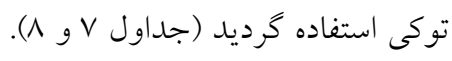

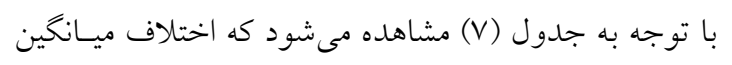

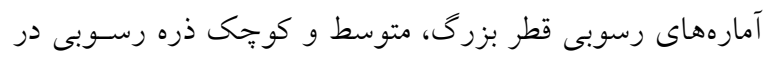

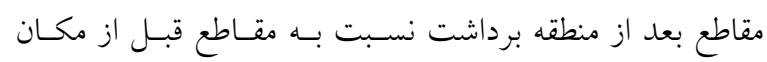
برداشت منفى بوده و بيانخر كاهش اين آمارههاى بعد از مكـان

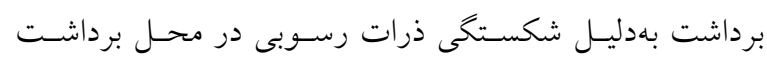

مقاطع قبل بوده و در محل برداشت نسبت بـه مقـاطع قبـل از

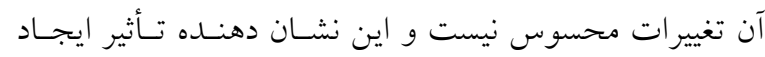

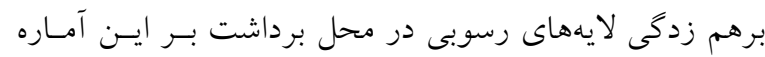

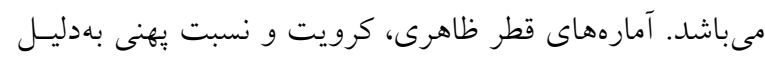

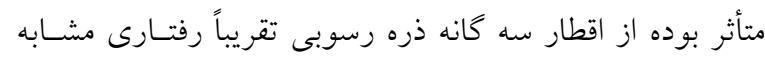

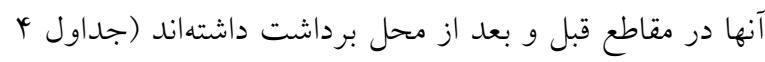

نتايج آزمون همخنى و نرمال بودن دادهها نشان دهنـــه ايسن

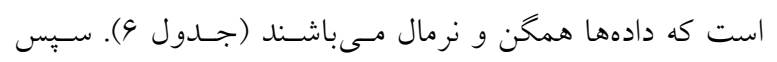

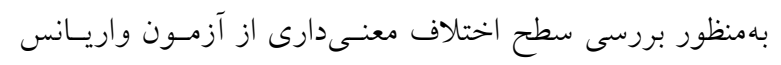




\begin{tabular}{|c|c|c|c|c|c|c|}
\hline \multirow{2}{*}{ آزمون ليون } & \multicolumn{2}{|c|}{ آزمون كلموكروف - اسميرنوف } & \multicolumn{2}{|c|}{ يار امترهاى نرمال } & \multirow{2}{*}{ تعداد } & \multirow{2}{*}{ رسوبى } \\
\hline & Sig. & Kolmogorov-Smirnov & انحر اف معيار & ميانخين & & \\
\hline $0 / 11$ & $0 / I V T$ & $0 / 14$ & $\mathrm{rV} / \mathrm{VQ}$ & $9 \mathrm{~V} / 99$ & $90 / 00$ & $\mathrm{a}$ \\
\hline س & $\circ / T T_{0}$ & & $r \Delta / \wedge \Delta$ & $\forall V / F V$ & $9 \% / 00$ & $\mathrm{~b}$ \\
\hline $0 / 14$ & $0 / 1 \mathrm{kr}$ &.$/ 09$ & Ir/Nr & $r q / 11$ & $9 \circ / 00$ & $\mathrm{c}$ \\
\hline D/Tr & OAYG & $0 / Y \Lambda$ & $0 / 01$ & $0 / 01$ & $90 / 00$ & $\mathrm{Rc}$ \\
\hline.$/ Q t^{r}$ & $0 / 4 r q$ & $0 / 14$ & $\circ / I V$ &.$/ 01$ & $90 / 00$ & $\mathrm{Sf}$ \\
\hline$\circ / 9 V$ & $\circ / \mu \wedge \circ$ & $\circ / 10$ & $r \mid / \wedge r$ & $40 / 19$ & $9 \circ / 00$ & $\mathrm{D}$ \\
\hline $0 / 94$ & $\circ / \Delta+1$ & $\circ / 00$ & $\circ / 11$ & $0 / 91$ & $90 / 00$ & $\mathrm{~S}$ \\
\hline $0 / 1 Y$ & $0 /|V|$ & $0 / 11$ & $0 / 90$ & $r / T l$ & $9 \% / 00$ & W \\
\hline
\end{tabular}

جدول V. نتايج مقايسه آمارى ويزگىهاى ريخت سنجى رسوبات در مقاطع قبل و بعد از محل برداشت با استفاده از آزمون توكى (A: مقاطع بعد از محل برداشت؛ B: مقاطع قبل از محل برداشت و C: محل برداشت)

\begin{tabular}{|c|c|c|c|c|c|c|c|c|c|c|c|c|c|c|}
\hline \multicolumn{14}{|c|}{ آمارههاى رسوبى } & \multirow{3}{*}{ مكمونه } \\
\hline \multicolumn{2}{|r|}{ W } & \multicolumn{2}{|r|}{$\mathrm{S}$} & \multicolumn{2}{|r|}{ D } & \multicolumn{2}{|c|}{ Sf } & \multicolumn{2}{|c|}{$\mathrm{c}$} & \multicolumn{2}{|r|}{$\mathrm{b}$} & \multicolumn{2}{|r|}{ a } & \\
\hline Sig. & ميانخًين & Sig. & ميانخًين & Sig. & ميانخين & Sig. & ميانخين اختلاف & Sig. & ميانخين & Sig. & ميانخين اختلاف & Sig. & ميانخين & \\
\hline.$/ 1$ & $-0 / \pi q *$ & $\%$ & $-\circ / \wedge^{*}$ & $\%$ & $-Y Y / \Lambda_{0} * *$ & $0 / 01$ & $-0 / 10 *$ & $\%$ & $|r /| r^{-}$ & $\%$ & $-T V / Q H^{\prime} *$ & $\%$ & $-\varphi \Delta / 9 \Lambda^{*}$ & B \\
\hline $0 / 19$ & $-0 / \mu_{\Lambda}$ & $\% / r$ & $-0 / 09 *$ & $\circ / 90$ & $-r / 0 Y$ & $\circ / 94$ & $-0 \% Y$ & $\circ / \mathrm{AV}$ & $-T / Y \varphi$ & $\circ / N a$ & $-\Delta / r \Delta$ &.$/ 10$ & $-r \circ / N Q$ & $\mathrm{C}$ \\
\hline $1 / 00$ & $-0 / \%$ &.$/ 94$ & $-0 / \%$ &.$/ 1$ & $-19 / V \Lambda^{*}$ & $\circ / 0 V$ & $0 / 14$ & $\% 4$ & $\begin{array}{c}- \\
10 / A V^{*}\end{array}$ & $\%$ \% & $-T Y / Y \Lambda^{*}$ & $0 / 04$ & $-T Q / T Y$ & B \\
\hline
\end{tabular}

جدول ^. نتايج مقايسه آماره Rc رسوبات در مقاطع قبل و بعد از محل برداشت با استفاده از آزمون دانكن

\begin{tabular}{|c|c|c|c|c|}
\hline Sig. & ميانخين & تعداد دادهها & مقاطع نمونهبردارى & آماره \\
\hline \multirow{3}{*}{$0 / Y Q 1$} & $0 / 0094$ & yo & B & \\
\hline & $0 / 0114$ & 10 & $\mathrm{C}$ & $\mathrm{Rc}$ \\
\hline & $0 / 0091$ & yo & A & \\
\hline
\end{tabular}

مى باشد. همخجنين اختلاف اين آمارههـاى در مكـان برداشـت و نشان نمىدهد.

بـا درنظـر كــفتن فاصـله بـين مقــاطع (جــدول () تغييـرات

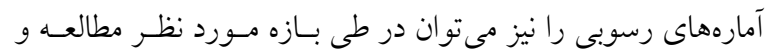

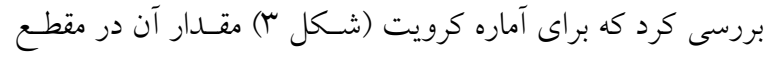
شماره ه (محل برداشت شن و ماسه) كاهش يافته است. آماره كرد درد شدكى نيز براساس شكل (T) بعد از مكان برداشت تا مطقع شماره

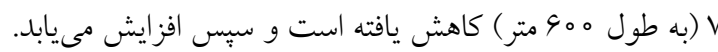

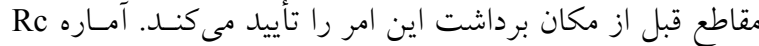

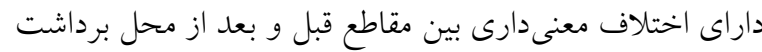

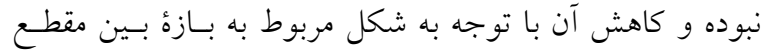

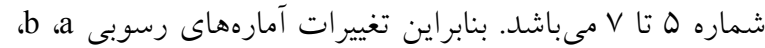

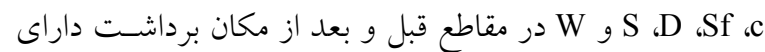
اختلاف معنى دارى است ولى آماره Rc اخستلاف معنسدارى را 
نشريه علوم آب و خاك (علوم و فنون كثاورزى و منابع طبيعى) / سال بيست و يكى / شماره سه/ باييز وهسا
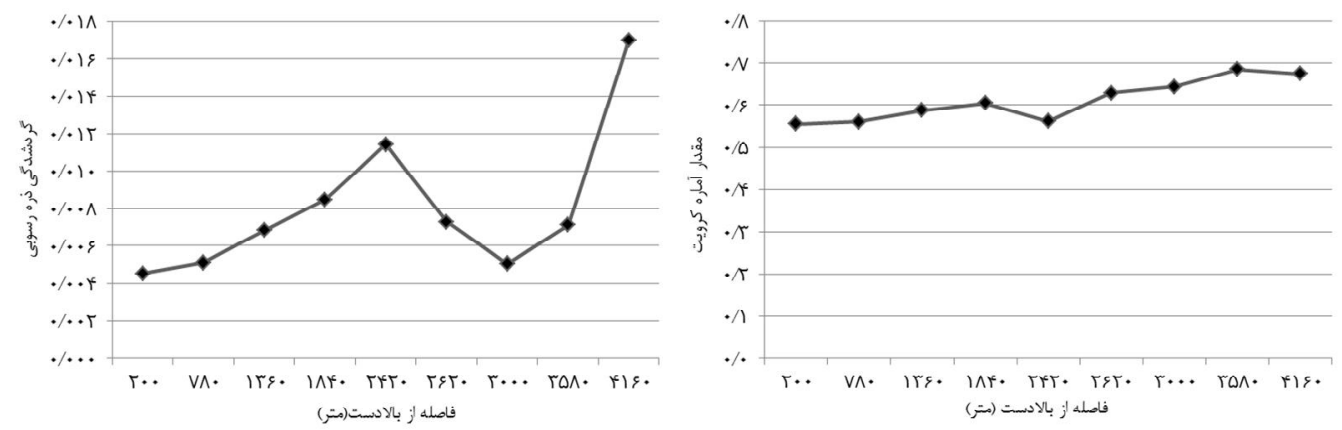

شكل r. تغييرات مقدار آماره كرويت و گردشدگى در مقاطع مورد بررسى در جهت پايين دست رودخانه

\section{تغييرات آماره كرويت از بالادست به سمت بايين دست در نتيجه گيرى}

اين تحقيق با هدف بررسى اثـرات برداشـت شـن و ماسـهـ بـر

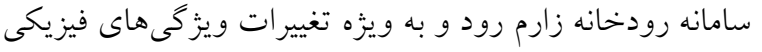
رسوبات كه يكى از مهمترين فاكتورها در تعيين رفتار رودخانه

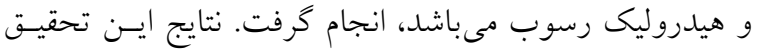

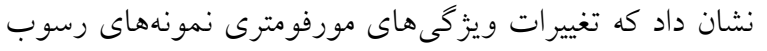
بستر رودخانه در محل برداشت شن و ماسه قابل ملاحظه است. همجنين برداشت شن و ماسه از بستر رودخانه موجب اخستلال

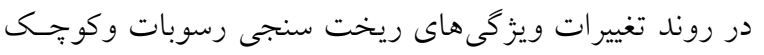

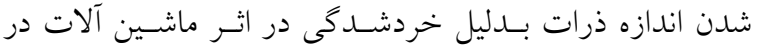

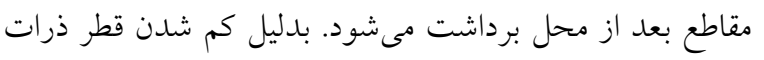

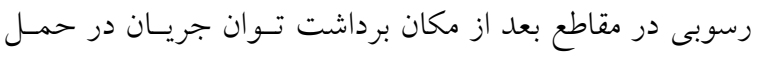

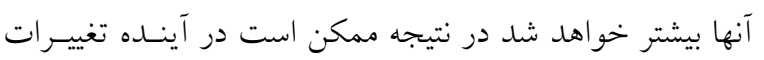

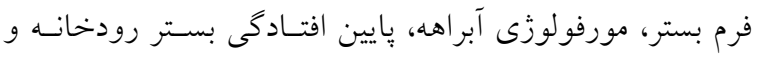

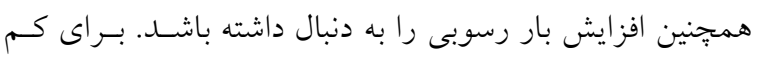

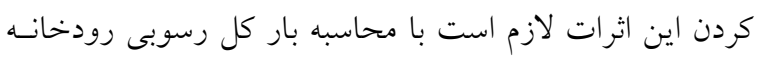

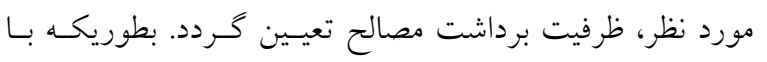

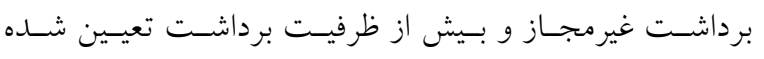
تغييرات مورفولوزيكى و هيدروليكى محتمل خواهد بود.

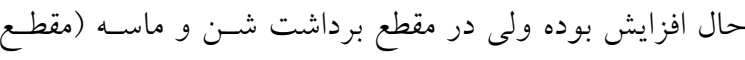

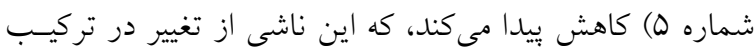

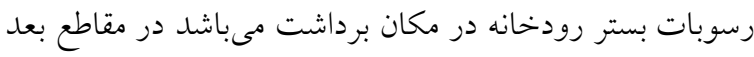
از مكان برداشت، رودخانه فعاليت طبيعى خـود را ادامـه داده و

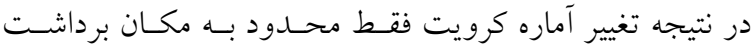

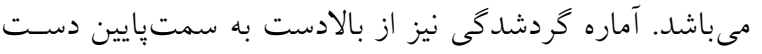

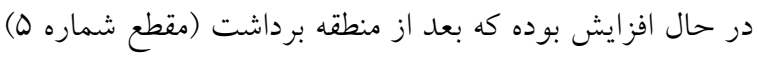

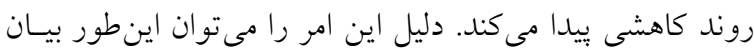

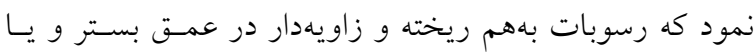

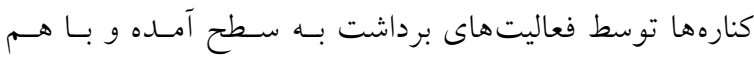

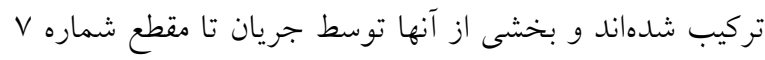

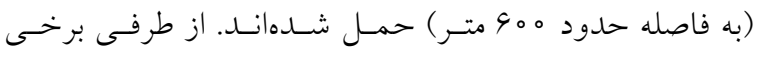
رسوبات در مقطع ه (محل برداشت شن و ماسه) بهدليل فعاليت

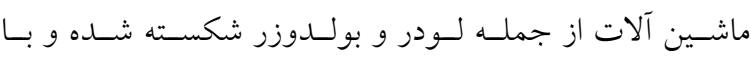
كردشدكى كمترى در سطح ظاهر شده و در اختيار جريان براى

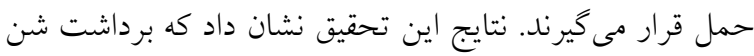

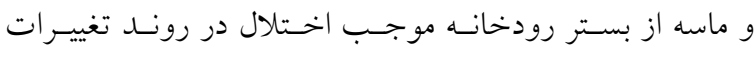
ويزگ هاى ريخت سنجى رسوبات بستر رودخانه در بازه مورد

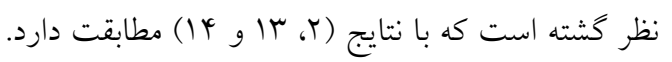




$$
\begin{aligned}
& \text { منابع مورد استفاده }
\end{aligned}
$$

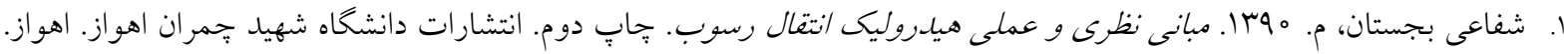

$$
\begin{aligned}
& \text { ص } \Delta \text { ص } \\
& \text { ז. صادقى، س. ح. ر. وع. و. خالدى درويشان. هیَ|. بررسى نقش برداشت شن و ماسه بر افزايش توان حمـل رسـوب رودخانـه. } \\
& \text { هفتمنى سمينار بين المللى مهندسى رودخانه، اهواز، دانشخاه شهيد جِمران اهواز. ^ ص. ص. } \\
& \text { r. صادقى، س. ح. ر.، س. قره محمودلى وع. و. خالدى درويشان. سهץ|. تغييريذيرى مقدار و ويزگى هاى دانهبندى و ريخت سنجى }
\end{aligned}
$$

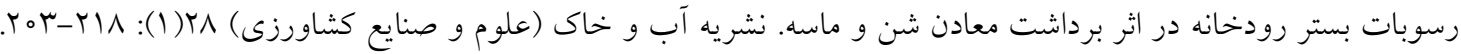

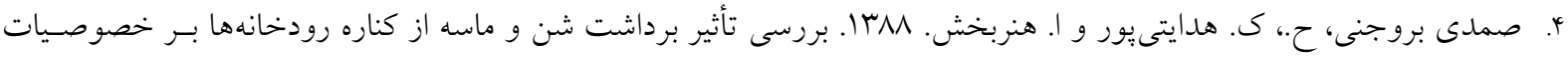

$$
\begin{aligned}
& \text { هيدروليكى جريان با استفاده از مدل HEC-RAS (مطالعه موردى: رودخانه خشكه رود فارسان). هشتمين سـمينار بـين المللى } \\
& \text { مهندسى رودخانه، اهواز، دانشخاه شهيد جّمران اهواز. } 9 \text { ص. }
\end{aligned}
$$

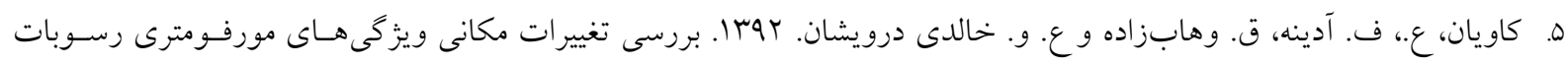

$$
\begin{aligned}
& \text { بستر در جهت ياياب رودخانه (مطالعه موردى: حوزه آبخيز قلعهسر سارى). نشريه مرتع و آبخيزدارى، مجله منابع طبيعى ايسران } \\
& .1 M \mid-14 F:(1) 99
\end{aligned}
$$

6. Ako, T. A., U. S. Onoduku, S. A. Oke, B. I. Essien, F. N. Idris, A. N. Umar and A. A. Ahmad. 2014. Environmental effects of sand and gravel mining on land and soil in Luku, Minna, Niger State, North central Nigeria. J. of Geosciences and Geomatics 2(2): 42-49.

7. Ashraf, M. A., M. J. Maah, I. Yusoff, A. Wajid and K. Mahmood. 2011. Sand mining effects, causes and concerns: A case study from Bestari Jaya, Selangor, Peninsular Malaysia. Sci. Res. Essays 6(6): 1216-1231.

8. Ayenagbo, K., J. N. Kimatu, J. Gondwe and W. Rongcheng. 2011. The Transportation and marketing implications of sand and gravel and its environmental impact in Lome-Togo. J. of Econ. and Int. Finance 3(3): 125-138.

9. Cao, Z. and G. Pender. 2004. Numerical modeling of alluvial rivers subject to interactive sediment mining and feeding. Advanced in Water Resour. 27(5): 533-546.

10. Chang, H. 1998. Generalized computer program fluvial-12 mathematical model for erodible channels. user manual, PP 58. Rancho Santa Fe, CA 92067-4492.

11. Dogan, E., S. Isik, L. Kalin, M. Sasal and N. Agriralioglu. 2008. Effect of anthropogenic activities on the Lower Sakarya River. Catene 75: 172-181.

12. Frip, J. B. and P. Diplas. 1993. Surface sampling in gravel stream. J. of Hyd. Eng. 119(4): 473-490.

13. Healy, T. and K. Wo. 2002. Sediment characteristics and bed level changes in relation to sand extraction and damming of a sand-gravel river: The lower Waikato River, New Zealand. J. of Hyd. (NZ) 41(2): 175-196.

14. Jose Luis Lopez, S. 2004. Channel response to gravel mining activities in mountain rivers. J. of Mountain Sci. 1(3): 264-269.

15. Kim, C. 2005. Impact analysis of river aggregate mining on river environment. Water Eng. 9(1): 45-48.

16. Kinghton, A. D. 1999. The gravel-sand transition in disturbed catchment. Geomorphology 27(3-4): 325-341.

17. Kondolf, G. M. 1997. Hungry water: effects of dams and gravel mining on river channels. Environmental Manage. 21(4): 533-551.

18. Lagasse, P. F., D. B. Simons and B. P. Winkely. 1980. Impact of gravel mining on river system stability. J. of the Waterway Port Costal and Ocean Division 106(3): 389-404.

19. Leeder, M. R. 1988. Sedimentology: process and product. Fletcher \& Son Ltd. 344 pages.

20. Marston, R. A., J. P. Bravard and T. Green. 2003. Impacts of reforestation and gravel mining on the Malnant River, Haute-Savoie, French Alps. Geomorphology 55(1-4): 65-74.

21. Martin-Vide, J. P., C. Ferrer-Boix and A. Ollero. 2010. Incision due to gravel mining: modeling a case study from the Gállego River, Spain. Geomorphology 117: 261-271.

22. McDonald, S. J., A. D. Watts, S. Laswell and J. M. Brooks. 2002. Determination of particle size distribution (gravel, sand, silt and clay) in sediment samples. College Station, Texas 77845. 22 pages.

23. Mosely, M. P. and D. S. Tindale. 1985. Sediment variability and bed material sampling in gravel-bed Rivers. Earth Sur. Proc. Land. 10(5): 465-482.

24. Padmalal, D., K. Maya, S. Sreebha and R. Sreeja. 2008. Environmental effects of river sand mining: a case from the 
river catchments of Vembanad lake, Southwest coast of India. Environ. Geology 54: 879-889.

25. Rinaldi, M. 2003. Recent channel adjustments in alluvial rivers of Tuscany, Central Italy. Earth Sur. Proc.and Lan. 28(6): 587-608.

26. Rinaldi, M., B. Wyzga and N. Surian. 2005. Sediment mining in alluvial channels: physical effects and management perspectives. River Res. Appl. 21(7): 805-828.

27. Rovira, A., R. J. Batalla and M. Sala. 2005. Response of a river sediment budget after historical gravel mining (the lower Tordera, NE Spain). River Res. and Appl. 21: 829-847.

28. Simons, D. B. and P. F. Lagasse. 1976. Impact of dredging on river system morphology. In Proceedings of Conference Rivers. American Society of Civil Engineers: New York, 435-457.

29. Sracek, O., K. Bohdan, M. Martin, M. Vladimir, V. Frantisek, V. Zbynek and N. Imasiku. 2012. Mining-related contamination of surface water and sediments of the Kafue River drainage system in the Copperbelt district, Zambia: An example of a high neutralization capacity system. J. of Geochem. Explor. 112: 174-188.

30. Surian, N. and M. Rinaldi. 2003. Morphological response to river engineering and management in alluvial channels in Italy. Geomorphology 50: 307-326.

31. Willis, K. G. and D. Garrod. 1999. Externalities from extraction of aggregates regulation by tax or land-use controls. Resour. Policy 25: 77-153. 


\title{
Investigation the Effect of Sand and Gravel Mining on Bed Sediment Morphometric Characteristics (Case Study: Zaremrood River, Mazandaran Province)
}

\author{
S. H. Roshun ${ }^{1 *}$, Gh.Vahabzadeh ${ }^{1}$, K. Solaimani ${ }^{1}$ and A. Khaledi Darvishan ${ }^{2}$
}

(Received: Feb. 09-2016; Accepted: Jan. 04-2017)

\begin{abstract}
Sand and gravel mining from the most of our country rivers causes morphological, hydrological and geomorphological changes in these rivers. This study investigates the effects of removal of sand and gravel from the river bed on sedimentological features of Zaremrood River in Mazandaran province. For this purpose, by determining four sections before and four sections after the sand removing point, the river bed sediments sampling in combined approach and in a plot within the river were performed and sedimentology features such as the large, medium and small diameters ( $a, b$ and $c)$, roundness $\left(R_{c}\right)$, form factor $\left(S_{f}\right)$, normal diameter $(D)$, sphericity $(S)$, and width ratio $(W)$, were measured and calculated in the laboratory and analyzed by SPSS software. The results showed that the variations of sediment statistics $\mathrm{a}, \mathrm{b}, \mathrm{c}, \mathrm{Sf}, \mathrm{D}, \mathrm{S}$ and $\mathrm{W}$ in the pre- and post- harvest location has a significant difference but the Rc statistic does not show any significant difference. The reduction of the triple diameters after the excavation site is caused by the fracture of the sediments in the mining area, so that the sphericity of grains also decreased in the mining area. Roundness of sediment particles after the excavation site is decreasing up to 600 meters reach and then it tends to increase.
\end{abstract}

Keywords: Sand and Gravel Mining, Combined Approach, Sediment Morphometric, and Mazandaran Province.

1. Dept. of Watershed Manage. Eng., Faculty of Natural Resour. Sari Univ. of Agric. Sci. and Natural Resour., Sari, Iran.

3. Dept. of Watershed Manage. Eng., Faculty of Natural Resour. and Marine Sci., Tarbiat Modarres Univ., Tehran, Iran.

*: Corresponding Author, Email: H.Roshun@stu.sanru.ac.ir 